\title{
Electrocardiographic evidence of myocardial salvage after thrombolysis in acute myocardial infarction
}

\author{
K J HOGG, K R LEES, R S HORNUNG, C A HOWIE, F G DUNN, W S HILLIS \\ From the Department of Materia Medica, University of Glasgow, Stobhill General Hospital, Glasgow
}

SUMMARY There is a need for a simple clinical measurement that will indicate the extent of myocardial salvage after successful thrombolysis. This study examined whether coronary artery reperfusion reduced the infarct size as assessed electrocardiographically after thrombolytic treatment. The sum of the $\left(\sum\right)$ ST segment area in leads showing ST segment elevation in the 12 lead electrocardiogram at presentation was used as an index of potential myocardial injury (initial ischaemic index). The evolved infarct size at $48 \mathrm{~h}$ was assessed by a QRS scoring system. Two groups of patients, both admitted with anterior myocardial infarction within $6 \mathrm{~h}$ of onset, were studied. Group $1(n=35)$ received analgesia only and group $2(n=33)$ received thrombolytic treatment either by the intracoronary (streptokinase, $n=13$ ) or intravenous route (anistreplase, $\mathbf{n}=20$ ). Reperfusion was assessed angiographically. The mean (SD) potential infarct size assessed by the initial ischaemic index was similar in both groups (group $1, \sum$ ST area $=115(60) \mathrm{mm}^{2}$ and group $2=126\left(77 \mathrm{~mm}^{2}\right)$. The QRS score representing evolved infarct size was significantly lower in the treated group (4.1 (2.5)) than in group $1(7 \cdot 8(2 \cdot 6))$. The $95 \%$ confidence intervals for QRS scores based on the admission $\sum$ ST area from patients with successful reperfusion were applied to a third set of patients $(n=22)$ to test the ability of the admission ST area (myocardial injury) to predict the QRS score accurately. While patients with successful reperfusion had significantly lower QRS scores than those who did not (4.5(3.1) v 9.3(3.4)), the wide confidence intervals caused by inter-individual variability precluded an accurate prediction of the QRS score in an individual from the $\sum S T$ area at time of presentation. There was no difference in infarct size in patients treated early $(\leqslant 3 \mathrm{~h})(\mathrm{QRS}$ score $4 \cdot 2(2 \cdot 8))$ or later $(3-6 \mathrm{~h})(4 \cdot 1(2 \cdot 1))$.

This study provides evidence that sequential electrocardiographic changes are reduced in patients with anterior myocardial infarction who achieve reperfusion after thrombolytic treatment and that this benefit is shown with treatment given up to six hours after infarct onset. None the less, the relation between the initial ischaemic index and the evolved QRS score has wide confidence intervals, reflecting inter-individual variability, and does not allow the prediction of a QRS score in an individual patient.

Thrombolytic treatment is being widely used in patients with acute myocardial infarction; the aims of treatment are coronary artery reperfusion ${ }^{12}$ and maintenance of left ventricular function. ${ }^{3}$ Brief, high dose intravenous infusion of streptokinase is a feasible treatment that may be given in all coronary care units and has reduced mortality in hospital. ${ }^{45}$

Non-invasive methods to confirm both coronary artery reperfusion and the degree of myocardial salvage would be helpful in planning long term

Requests for reprints to Dr K J Hogg, Department of Materia Medica, Stobhill General Hospital, Glasgow G21 3UW.

Accepted for publication 16 February 1989 management. We have already reported on the use of 12 lead electrocardiograms to determine reperfusion. ${ }^{6}$ ST segment elevation is an electrocardiographic marker of coronary artery occlusion, and the natural course of the development of sequential electrocardiographic changes after clinical infarction has been intensively studied. ${ }^{78}$ This study investigates the serial changes in conventional 12 lead electrocardiograms during acute myocardial infarction. It compares the functional electrophysiological changes in controls with the changes in those who have obtained coronary artery reperfusion after thrombolytic treatment. The aim was to investigate, by using the admission electrocardiogram as an index of myocardial injury, whether there is a predictable 
reduction in the electrocardiographic indices of myocardial infarct size in patients in whom reperfusion was successful.

\section{Patients and methods}

We studied three groups of patients. All groups entered the study within six hours of the onset of cardiac pain and had confirmatory electrocardiographic evidence of acute anterior myocardial infarction (ST elevation $\geqslant 1 \mathrm{~mm}$ in the standard leads 1 and aVL or $2 \mathrm{~mm}$ ST elevation in at least two precordial leads). Patients were excluded if they had sustained a previous myocardial infarction or had electrocardiographic changes that invalidated ST segment and $Q$ wave analysis, including bundle branch block or pacemaker dependence.

Group 1 were historical controls who sustained an acute anterior myocardial infarction, but received no treatment other than conventional analgesia. They were admitted to our coronary care unit (from 1976 to 1979) before the introduction of routine thrombolytic treatment. All patients had prospective forms filled out detailing patient identification, clinical features on presentation, examination findings, treatment administered, and final diagnosis. These data were recorded on punch cards and stored in a mainframe computer. All electrocardiographic and haemodynamic tracings performed were stored separately as hard copy. This control group had no complications requiring specific cardioactive agents and had not received routine administration of any drugs that might influence myocardial infarct sizespecifically $\beta$ blockers, calcium channel blockers, or nitrates. The electrocardiographic changes measured therefore represent those occurring in a patient group with acute anterior myocardial infarction without cardiogenic shock or haemodynamic decompensation.

Group 2 consisted of patients who received thrombolytic treatment with the agent of our current thrombolysis protocol. Both groups are similar with respect to age, sex, and time to presentation (table 1 ). Exclusion criteria for patients receiving thrombolytic treatment were: a history of bleeding diathesis; a recent cerebrovascular accident ( $\leqslant 6$ months); peptic ulceration; severe renal or hepatic disease; severe hypertension.

Patients in group 2 received either intracoronary streptokinase (250 000-500 000 units over $1 \mathrm{~h}$ $\mathrm{n}=13$ ) or an intravenous bolus dose of $30 \mathrm{mg}$ anistreplase $(n=20)$. Coronary artery patency was determined by selective coronary arteriography, performed during treatment when intracoronary streptokinase was given $60-90$ minutes after administration of intravenous anistreplase. The coronary arteriograms were read independently by@ two of the hospital clinicians who were not $_{c}^{\text {? }}$ participating in the study. The patency of the infarct related vessel was decided and presence or absence of ${ }^{5}$ ? reperfusion was established. It was consideredo unethical to perform emergency angiography in the $\overline{0}$ group 1 patients who received only opiate analgesia, $\frac{\vec{\rho}}{\vec{\rho}}$ and therefore the incidence of coronary artery ${ }^{\Phi}$ patency at time of admission and of spontaneous reperfusion is unknown. ${ }^{9}$

Group 3 consisted of 22 patients (19 men, three. women, age range $32-69$, mean age 54 years) receiv- $\vec{\omega}$ ing either 1.5 megaunits intravenous streptokinase $\omega$ over $1 \mathrm{~h}$ or $30 \mathrm{mg}$ intravenous anistreplase over five minutes. Reperfusion was assessed angiographicallyo at 90 minutes after the start of treatment in all cases. $\cdot \vec{\sigma}$

ELECTROCARDIOGRAPHIC ANALYSIS

After admission to the coronary care unit, 12 lead응 electrocardiograms were obtained on a HewlettPackard Cardiograph 4700A. The chest lead posi- $-\subseteq$ tions were marked to ensure reproducibility. The ST segment area was calculated for each lead showing $\overrightarrow{-}$ ST elevation (1 mm in the limb leads or $2 \mathrm{~mm}$ in theo precordial leads taken at the J point) and measured as the area above the isoelectric line from the $J$ point too the end of the $T$ wave. The scores for all leads were summed as an index of myocardial injury or ischaemia, reflecting potential infarct size.

A second electrocardiogram was taken at 48 hours after the onset of symptoms and the evolved infarct $\overrightarrow{\bar{O}}$ size was measured by the QRS scoring system 3 developed by Wagner et $a l^{10}$ and further assessed in postinfarction patients by Palmeri et al. ${ }^{11}$ This QRS? scoring system is based on a 29 point system that depends upon the duration of $R$ and $Q$ waves and the ratios of $R / S$ and $R / Q$ amplitudes. A good correlation:between anatomical anterior infarct size and this 3 . QRS score has been shown ${ }^{12}$ and Palmeri et al showed an inverse correlation between the QRS score and left ventricular ejection fraction measured by radionuclides. ${ }^{11}$ The higher the QRS score, the more extensive the infarct; a small QRS scoreo indicates a limited infarct.

Table 1 Data on study groups

\begin{tabular}{|c|c|c|c|c|c|c|}
\hline & No & $\begin{array}{l}\text { Sex } \\
M\end{array}$ & $\boldsymbol{F}$ & $\begin{array}{l}\text { Mean } \\
\text { age } \\
(y)\end{array}$ & Treatment & $\begin{array}{l}\text { Mean time } \\
\text { to } \\
\text { presentation }\end{array}$ \\
\hline $\begin{array}{l}\text { Group } 1 \\
\text { Group } 2\end{array}$ & $\begin{array}{l}35 \\
33\end{array}$ & $\begin{array}{l}29 \\
22\end{array}$ & $\begin{array}{r}6 \\
11\end{array}$ & $\begin{array}{l}55 \cdot 5 \\
57 \cdot 3\end{array}$ & $\begin{array}{l}\text { Control }(\mathbf{n}=35) \\
\text { IC streptokinase } \\
\quad(n=13) \\
\text { IV anistreplase } \\
\quad(n=20)\end{array}$ & $\begin{array}{r}3 \mathrm{~h} 28 \mathrm{~min} \\
(96 \mathrm{~min}) \\
2 \mathrm{~h} 40 \mathrm{~min} \\
(87 \mathrm{~min})\end{array}$ \\
\hline
\end{tabular}

IC, intracoronary; IV, intravenous. 

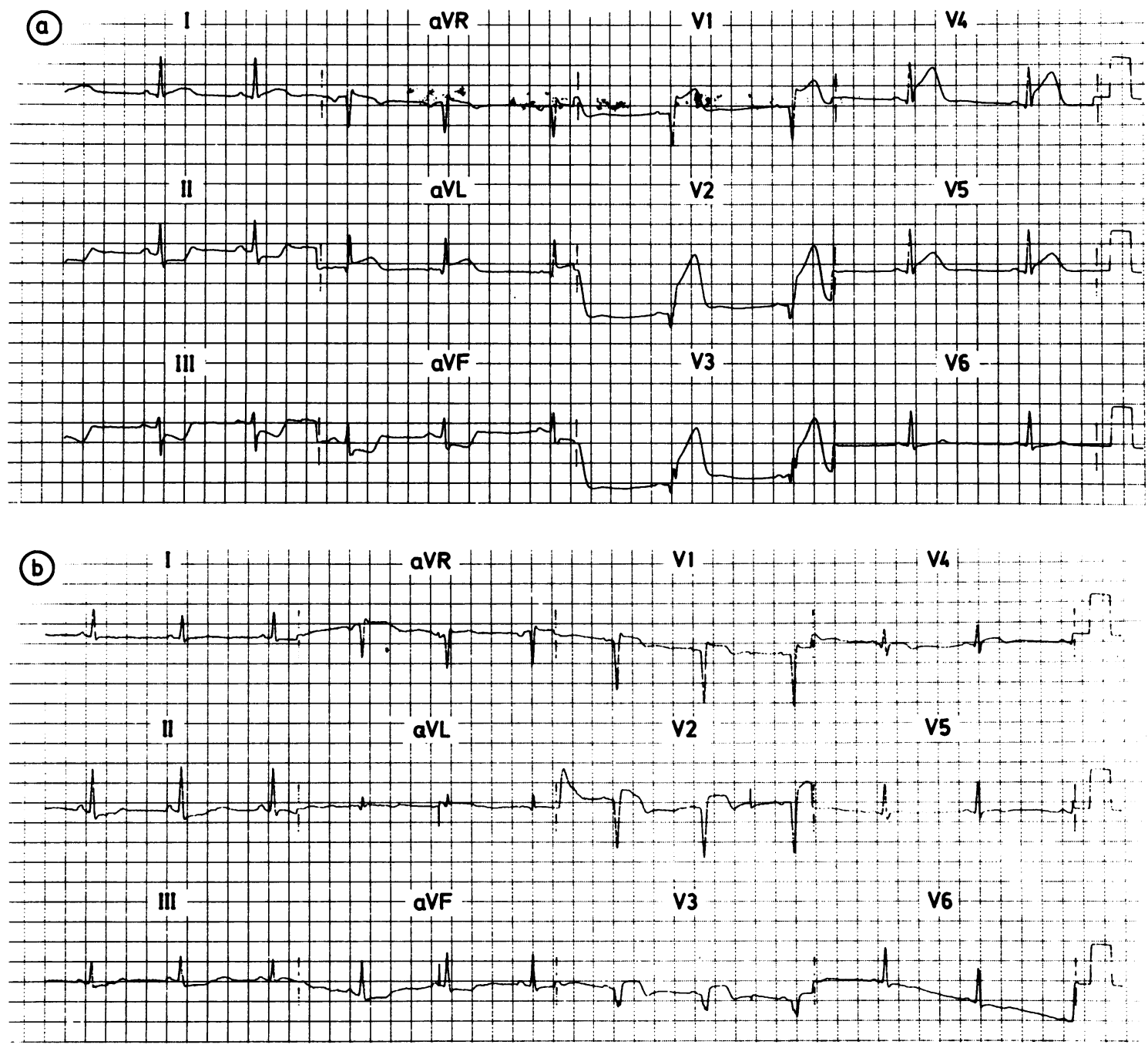

Fig 1 (a) Electrocardiogram of a patient with acute anterior myocardial infarction who was admitted within 2 h 25 min after onset of pain $\left(\Sigma S T\right.$ area $\left.=218 \mathrm{~mm}^{2}\right)$. (b) Same patient 48 hours after admission, after successful thrombolytic reperfusion. The $Q R S$ score is 3.

STATISTICAL ANALYSIS

We used Student's unpaired $t$ test to compare groups. Linear regression was performed with a statistical package on a Nodecrest computer, and an F test was applied to test the regression lines. Prediction intervals of $Q R S$ scores for future patients were calculated on the basis of data from the known data on patients showing reperfusion. This predicts the QRS score that would be expected had reperfusion occurred.

\section{Results}

Figures $1 \mathrm{a}$ and $1 \mathrm{~b}$ show a representative electrocardiograph on admission and at $\mathbf{4 8}$ hours from which the $\sum S T$ segment area and the QRS scores were calculated. The degree of evidence of ischaemia on the electrocardiogram at presentation was similar in both groups $\left(\sum \mathrm{ST}\right.$ area-group $1,115(60) \mathrm{mm}^{2}$; group 2, $126(77) \mathrm{mm}^{2}$ ). This indicates that both groups had comparable myocardial ischaemia and 


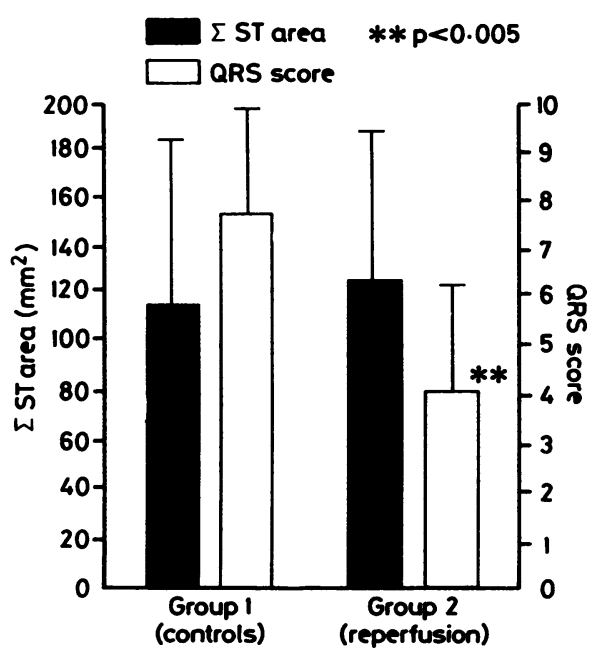

Fig 2 Relation between $\Sigma S T$ area (mean (SD)) on presentation and subsequent $Q R S$ score in group 1 (controls) and group 2 (reperfusion). There is a significant reduction in the $Q R S$ score in patients achieving reperfusion.

potential infarct size. Of the patients in group 2, who received thrombolytic treatment, $11 / 13$ receiving intracoronary streptokinase achieved successful reperfusion and 19/20 receiving intravenous anistreplase were found at angiography to have a patent infarct related vessel (left anterior descending). At 48 hours the evolved infarct size as assessed by the QRS score was significantly lower in those patients in whom reperfusion was obtained than for the control group (4.1 (2.5) compared with 7.8 (2.6)) (p < 0.01). Figure 2 shows the relation between myocardial ischaemia at admission ( $\sum$ ST area) and eventual infarct size for both the control group and those patients achieving reperfusion.

Only three patients in group 2 did not show reperfusion and therefore we did not do a formal statistical analysis to compare the electrocardiographic score of the reperfusion group with the non-reperfusion group. The non-reperfused patients, however, showed $Q$ wave development similar to the control group (table 2 ). The patients in group 2 were further divided according to the interval between the onset of cardiac pain and the

Table 2 Mean values and standard deviations for $\Sigma S T$ area and QRS scores for groups 1 and 2

\begin{tabular}{llll}
\hline & $\begin{array}{l}\text { Group 1 } \\
\text { (Control) }\end{array}$ & Group 2 & \\
\cline { 3 - 4 } & Reperfusion & Non-reperfusion \\
\hline S ST area & $\mathrm{n}=35$ & $\mathrm{n}=30$ & $\mathrm{n}=3$ \\
QRS score & $115(60)$ & $126(77)$ & $279(44 \cdot 7)$ \\
\hline
\end{tabular}

time to thrombolytic treatment: group $2 a \leqslant 3 \mathrm{~h} \Phi$ $(n=16)$, group $2 b>3 \mathrm{~h}$ but $\leqslant 6$ hours $(n=14)$. $\mathrm{C}$ The values at presentation for $\sum$ ST segment area were $142(82) \mathrm{mm}^{2}$ and $107(70) \mathrm{mm}^{2}$ respectively (NS). The evolved infarct size scores were noto significantly different for the two groups (group 2a, 을. $4 \cdot 2(2 \cdot 8)$; group $2 b, 4 \cdot 1(2 \cdot 1)$.

Figure 3 shows a scatter diagram of the individual $\stackrel{\circ}{\circ}$ scores for group 1 and group 2 with the respective linear regressions $\left(Q R S=4.6+0.027 \times \sum S T\right.$ area, and $\mathrm{QRS}=1.6+0.020 \times \sum \mathrm{ST}$ area). These. regressions describing each group separately fit the $\vec{\omega}$ data better than a single regression through all points $\stackrel{\omega}{\circ}$ (p $<0.05)$.

The $95 \%$ prediction intervals for QRS scores were calculated using the reperfusion data for group $2 . \dot{\sigma}$ These intervals are shown in fig $\mathbf{4}$ with control data for group 1 superimposed. Many control patients $\stackrel{\infty}{\bullet}$ (51\%) had QRS scores within the $95 \%$ prediction? intervals for reperfused cases.

To investigate whether these intervals could be $c$ used accurately to predict QRS scores in individual patients, group 3 was used as a test group. The $\vec{\oplus}$ intervals were used to predict the QRS scores 00 expected if reperfusion had occurred in the new. patients. Out of 22 patients given thrombolytic treatment, 11 obtained a patent artery 90 minutes after treatment, and 11 did not. Both subgroups had similar degrees of myocardial injury on presentation $\frac{\mathbb{Q}}{\Phi}$ $\left(\sum S T\right.$ area $=147(74) \mathrm{mm}^{2}$ (reperfusion group) and $\stackrel{\varnothing}{\circ}$ $171(76) \mathrm{mm}^{2}$ (non-reperfusion group) (NS). Patients $\overrightarrow{\vec{O}}$ who obtained reperfusion had lower QRS scores than 3 the group who did not $(4.5$ (3.1) v 9.3 (3.4)) $(p<0.01)$. Figure 5, however, shows that only five? of the 11 without reperfusion had values outside the prediction intervals for reperfused cases. All patients except one who achieved reperfusion fall within the prediction intervals shown. The wide inter- 3 individual variability does not allow the prediction of a QRS score for an individual.

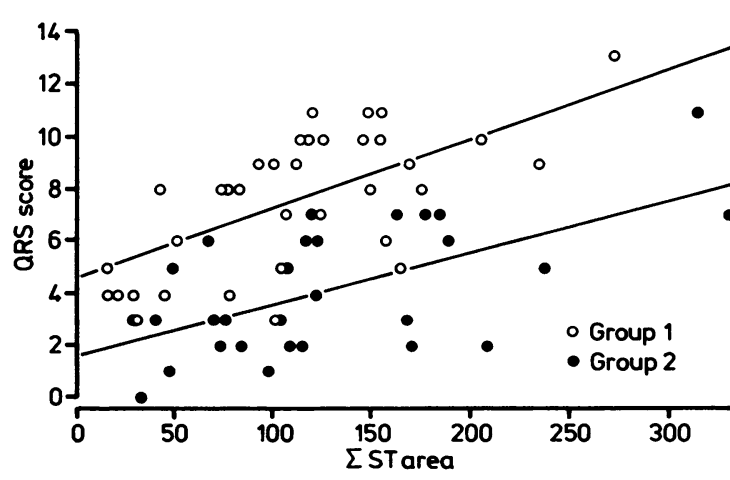

Fig 3 Scatter diagram with individual scores for group 1 and group 2 showing lines of linear regression for each group. 


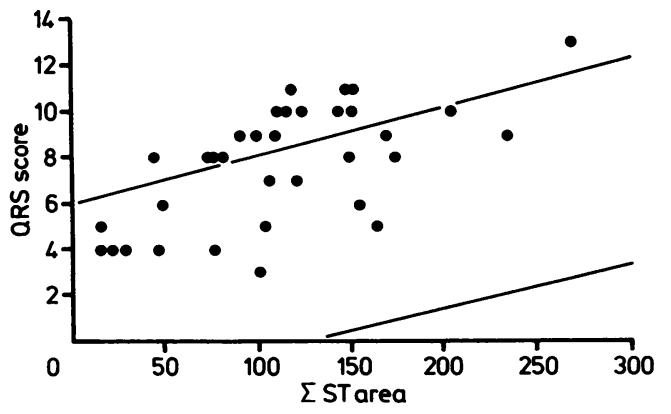

Fig $495 \%$ prediction intervals for $Q R S$ scores for patients achieving successful reperfusion. The results for group 1 (controls) are superimposed.

\section{Discussion}

This study shows that the sequential electrocardiographic changes are reduced in patients with acute anterior myocardial infarction who achieve coronary artery reperfusion after thrombolytic treatment. We studied whether this reduction in electrocardiographic infarct size could be used to predict individual QRS scores after reperfusion.

This was not a randomised study, but the control and intervention groups show similar distributions for sex, age, and time of presentation and similar values of ST elevation at presentation. Patients in the control group were not taking any drugs that could have influenced myocardial infarct size itself, and patients with cardiogenic shock or cardiac failure were also excluded. Selection for this group was therefore biased against inclusion of clinical subsets that may have had major myocardial damage. The electrocardiographic changes shown in this group therefore are the true natural course of acute anterior myocardial infarction. Because we considered it unethical to perform angiography in patients not

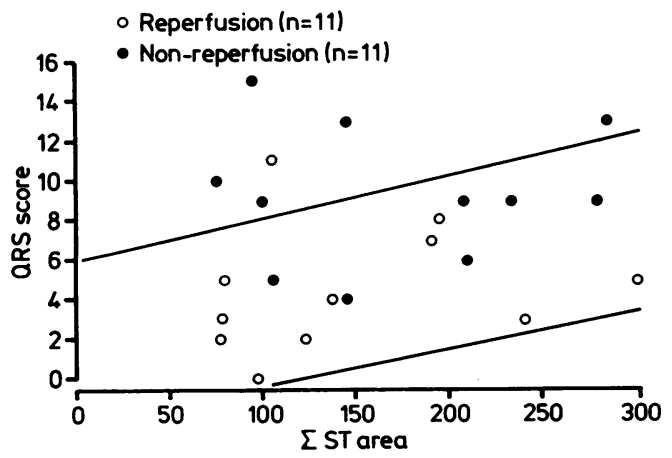

Fig 5 Results of $\Sigma S T$ area and $Q R S$ scores for group 3. being treated with thrombolysis, the control group may include patients with a subtotal coronary artery occlusion at the time of presentation or those who had spontaneous reperfusion.' Such coronary artery morphology may be associated with less eventual myocardial damage, and the inclusion of such individuals would again tend to bias results against finding a difference in evolved QRS scores.

It has long been recognised that ST segment elevation is an electrocardiographic marker of coronary artery occlusion. ${ }^{13}$ The conventional 12 lead electrocardiogram has been used principally for diagnosis, but some studies have followed the natural course of the sequential changes that occur during infarction. ${ }^{78}$ Selwyn et al showed that in patients with acute anterior myocardial infarction the precordial area of ST segment elevation at two hours was directly related to the extent of developed $Q$ waves at 24 hours after the onset of pain. ${ }^{8}$ An arbitrary time interval of $\mathbf{4 8}$ hours from presentation was chosen for the measurement of evolved infarct size in our study because $Q$ wave development is believed to be complete at this time. Interventions such as intraaortic balloon pumping ${ }^{14}$ and administration of atenolol $^{15}$ and hyaluronidase, ${ }^{16}$ designed to improve coronary artery perfusion and limit the degree of myocardial damage, have made use of changes in ST segments to indicate reduced ischaemia, and have used preservation of the $R$ wave and reduction in $Q$ wave development to indicate salvaged myocardium. We have already reported elsewhere on the specificity of ST segment reduction to predict coronary artery reperfusion during thrombolysis. ${ }^{617}$ This present study investigated the association of ST segment elevation on admission with the use of subsequent evolved QRS score in patients with acute myocardial infarction as an indicator of vessel patency.

Animal studies with an epicardial mapping system have shown a convincing correlation between ST segment changes, subsequent $Q$ wave development, myocardial creatine phosphokinase release, and histological evidence of necrosis. ${ }^{18}$ However, opinion is divided on the ability of ST segment elevation to predict either the severity or the extent of myocardial necrosis in humans. Precordial mapping techniques in patients with acute myocardial infarction found little relation between ST segment elevation and subsequent infarct size as assessed by creatine phosphokinase release. ${ }^{1920}$ Problems can arise because coronary artery occlusion is not the only stimulus to affect the ST segment: pericarditis ${ }^{21}$ and hyperkalaemia $^{22}$ may confuse the picture. Nevertheless, Askenazi et al reported that there is a predictable distribution of leads with ST elevation that ultimately develop signs of necrosis, and they suggested that a reduction in $\mathrm{Q}$ wave development would be 
of value in monitoring treatment designed to preserve myocardium. ${ }^{7}$ This has been confirmed in similar work by Yusuf et al. ${ }^{23}$

Our present study confirms that a reduction in $Q$ wave formation was associated with coronary artery reperfusion and that the reperfusion group had lower QRS scores than the control group. This is in contrast with the findings of Mikell et al who found that the QRS scores were the same irrespective of whether the patient had achieved successful reperfusion. ${ }^{24}$ Mikell et al did show an improvement in left ventricular ejection fraction if the patient had reperfusion, and they suggested that there was a lag between electrocardiographic changes and left ventricular recovery or function. In the patients that they studied there was a preponderence of inferior infarctions, and this may explain why a difference in QRS score was not seen. Previous studies have shown that both ST segment changes and QRS scores are more variable in patients with inferior infarcts. This may reflect the small number of leads that show changes with inferior infarction, and that therefore represent only a limited proportion of the underlying myocardium. ${ }^{25}$

Despite being able to show a reduction in QRS scores in these patients in whom there was reperfusion, when prediction intervals were calculated for this group the limits were so wide and overlap between groups such that clinical predictions regarding infarct size were not helpful. There may be several reasons for this degree of inter-individual variability. Hackworthy et al used the same QRS score as we did and showed that collateral formation resulted in a smaller than expected infarct size..$^{26}$ Only in patients with a totally occluded artery with no collaterals did the initial peak ST elevation correlate with electrocardiographic infarct size. Certainly the presence of collaterals may reduce the expected QRS score in patients with no anterograde flow, who would be classed as not having reperfusion. We know from De Wood et al that $15 \%$ of patients presenting within six hours of infarction will have a subtotal occlusion, and that there is a spontaneous reperfusion rate. ${ }^{9}$ Huey et al confirmed that patients with a naturally high patency rate at 10-13 days after infarction had better left ventricular function and less development of $Q$ waves. ${ }^{27}$ Similarly, Hackworthy et al showed a reduction in the expected QRS scores if there was a subtotal occlusion. ${ }^{26}$

It is not clear if the reduction in mortality in patients given thrombolytic treatment up to 24 hours after onset of symptoms ${ }^{5829}$ can be attributed to improvement in left ventricular function. Most studies that measure left ventricular function show benefit only if treatment is started in the first few hours. ${ }^{3031}$ In the present study beneficial changes in electrocadiographic indices of myocardial infarct size were shown even in those individuals given thrombolytic treatment 3-6 hours after the onset of symptoms. This suggests that functional benefit measured electrocardiographically may still be obtained if treatment can be started within six hours of the onset of cardiac pain. The potential for benefit may be present in those patients in whom coronary collaterals have previously developed or in whom acute infarction is associated with a subtotal coronary artery stenosis rather than a complete occlusion. ${ }^{32}$.

We used conventional 12 lead electrocardiograms $\vec{\exists}$ to show a significantly lower QRS score for the $\stackrel{\omega}{\sigma}$ evolved infarct in patients who achieved reperfusion after thrombolysis for acute anterior myocardial of infarction. Beneficial changes in this functional $\vec{\sigma}$ marker were obtained after successful reperfusion achieved by thrombolysis up to six hours from onset $\infty_{0}^{\infty}$ of pain. The wide inter-individual variability in $Q R S$ 을 scores makes prediction of infarct size on an individual basis unhelpful. This variability may be $c$ accounted for in part by degree of collateral supply, time to reperfusion, or by the presence of a subtotal occlusion at time of presentation. None the less, the $\stackrel{\infty}{\infty}$ reduction in QRS scores seen in patients who achieve ${ }^{\oplus}$ reperfusion after thrombolytic treatment may provide a non-invasive index of myocardial salvage for groups of patients.

We thank Beecham Pharmaceuticals for supplies of $\stackrel{\mathscr{D}}{\stackrel{\Phi}{ }}$ anistreplase.

\section{References}

1 Anderson JL, Marshall HW, Bray BE, et al. A $\vec{\oplus}$ randomized trial of intracoronary streptokinase in the treatment of acute myocardial infarction. $N$ Engl $J$ Med 1983;308:1312-8.

2 Kennedy JW, Ritchie JL, Davis KB, Stadius ML, Maynard C, Fritz JK. The Western Washington randomized trial of intracoronary streptokinase in acute myocardial infarction. $N$ Engl $J$ Med 은 1985;312:1073-8.

3 Reduto LA, Smalling RW, Freund GC, Gould KL. 으․ Intracoronary infusion of streptokinase in patients $\overline{\mathrm{N}}$ with acute myocardial infarction: effects of reper- $\Omega$ fusion on left ventricular performance. Am J Cardiol $N$ 1981;48:403-9.

4 GISSI Study Group. Effectiveness of intravenous $\omega$ thrombolytic treatment in acute myocardial infarction. Lancet 1986;i:397-401.

5 ISIS-2 Collaborative Group. Randomised trial of $\mathbb{\varnothing}$ intravenous streptokinase, oral aspirin, both; or ${ }^{+}$ neither among 17,187 cases of suspected acute $\square$ myocardial infarction: ISIS-2. Lancet 1988;ii: $349-60$.

6 Hogg KJ, Hornung RS, Howie CA, Hockings N, Dunn FG, Hillis WS. Electrocardiographic prediction of $\underset{\gamma}{\sigma}$ 
coronary artery patency following thrombolytic treatment in acute myocardial infarction: use of the ST segment as a non-invasive marker. Br Heart $J$ 1988;60:275-80.

7 Askenazi J, Maroko PR, Lesch M, Braunwald E. Usefulness of ST segment elevations as predictors of electrocardiographic signs of necrosis in patients with acute myocardial infarction. Br Heart $J$ 1977;39: 764-70.

8 Selwyn AP, Fox K, Welman E, Shillingford JP. Natural history and evaluation of $Q$ waves during acute myocardial infarction. Br Heart J 1978;40:383-7.

9 De Wood MA, Spores J, Notske R, et al. Prevalence of total coronary occlusion during the early hours of transmural myocardial infarction. $N$ Engl $J$ Med 1980;303:897-902.

10 Wagner GS, Freye CJ, Palmeri ST, et al. Evaluation of a QRS scoring system for estimating myocardial infarct size. I Specificity and observer agreement. Circulation 1982;65:342-7.

11 Palmeri ST, Harrison DG, Cobb FR, et al. A QRS scoring system for assessing left ventricular function after myocardial infarction. $N$ Engl $J$ Med 1982; 306:4-9.

12 Ideker RE, Wagner GS, Ruth WK, et al. Evaluation of a QRS scoring system for estimating myocardial infarct size. II Correlation with quantitative anatomic findings for anterior infarcts. Am J Cardiol 1982; 49:1604-14.

13 Pardee HEB. An electrocardiographic sign of coronary artery obstruction. Arch Intern Med 1920;26:244-57.

14 Leinbach RC, Gold HK, Harper RW, Buckley MJ, Austen WG. Early intra-aortic balloon pumping for anterior myocardial infarction without shock. Circulation 1979;58:204-10.

15 Yusuf S, Ramsdale D, Peto R, et al. Early intravenous atenolol treatment in suspected acute myocardial infarction[Abstract]. Lancet 1980;ii:273-6.

16 Maroko PR, Hillis LD, Muller JE, et al. Favourable effects of hyaluronidase on electrocardiographic evidence of necrosis in patients with acute myocardial infarction. N Engl J Med 1977;296:898-903.

17 Hogg KJ, Hornung RS, Hockings S, Dunn FG, Hillis WS. ST segment analysis as a non invasive predictive indicator of coronary artery reperfusion in acute myocardial infarction [Abstract]. Eur Heart $J$ 1985; 6(suppl 1):16.

18 Hillis LD, Askenazi J, Braunwald E. Use of changes in the epicardial QRS complex to assess interventions which modify the extent of myocardial necrosis following coronary artery occlusion. Circulation 1976;54:591-8.

19 Norris RM, Barratt-Boyes C, Heng MK, Singh BN. Failure of ST segment elevation to predict severity of acute myocardial infarction. $B r$ Heart $J$ 1976;38:
85-92.

20 Thompson PL, Katavatis V. Acute myocardial infarction: evaluation of praecordial ST segment mapping. Br Heart J 1976;38:1020-4.

21 Thadani V, Chopra MP, Aber CP, Portal RW. Pericarditis after acute myocardial infarction. $\mathrm{Br}$ Med J 1971;ii:135-7.

22 Levine HD, Wanzer SH, Merrill JP. Dialysable currents of injury in potassium intoxication resembling acute myocardial infarction or pericarditis. Circulation 1956;13:29-36.

23 Yusuf S, Lopez R, Maddison A, et al. Value of electrocardiogram in predicting and estimating infarct size in man. Br Heart $J$ 1979;42:286-93.

24 Mikell FL, Petrovich J, Snyder MC, et al. Reliability of $Q$ wave formation and QRS score in predicting regional and global left ventricular performance in acute myocardial infarction with successful reperfusion. Am J Cardiol 1986;57:923-6.

25 Savage RM, Wagner GS, Ideker RE, Podolsky SA, Hackel DB. Correlation of post mortem findings with electrocardiographic changes in patients with myocardial infarction. Circulation 1977;55:279-85.

26 Hackworthy RA, Vogel MB, Harris PJ. Influence of infarct artery patency on the relation between initial ST segment elevation and final infarct size. Br Heart $J$ 1986;56:222-5.

27 Huey BL, Gheorghiade M, Crampton RS, et al. Acute non- $Q$ wave myocardial infarction associated with early ST segment elevation: evidence for spontaneous coronary reperfusion and implication for thrombolytic trials. J Am Coll Cardiol 1987;9:18-25.

28 Stampfer MJ, Goldhaber SZ, Yusuf S, Peto R, Hennekens CH. Effect of intravenous streptokinase on myocardial infarction. $N$ Engl J Med 1982; 307:1180-2.

29 Yusuf S, Collins R, Peto R, et al. Intravenous and intracoronary fibrinolytic therapy in acute myocardial infarction: overview of results on mortality, reinfarction and side-effects from 33 randomised controlled trials. Eur Heart J 1985;65:556-85.

30 Sheehan FH, Mathey DG, Schofer J, et al. Effect of intervention in salvaging left ventricular function in acute myocardial infarction-a study of intracoronary streptokinase. Am J Cardiol 1983;52:431-8.

31 Ritchie JL, Cerqueira M, Maynard C, Davis IC, Kennedy JW. Ventricular function and infarct size: The Western Washington Intravenous Streptokinase in Myocardial Infarction Trial. J Am Coll Cardiol 1988;11:689-97.

32 Rogers WT, Hood WP, Mantle JA, et al. Return of left ventricular function after reperfusion in patients with myocardial infarction: importance of subtotal stenoses or infarct collaterals. Circulation 1984; 62:338-49. 